\title{
Penerapan Model Pembelajaran OPEK Fisika pada Materi Suhu dan Kalor dan Pengaruhnya terhadap Practical Skill Siswa SMA
}

\author{
Afriyanti ${ }^{1}$, Yosaphat Sumardi \\ ${ }^{1}$ Program Pascasarjana Universitas Negeri Yogyakarta \\ ${ }^{2}$ FMIPA Universitas Negeri Yogyakarta \\ Email : afriyanti11@gmail.com
}

\begin{abstract}
The contribution of physics instruction in the schools to face the ASEAN Economic Community can be realized by applying the instruction model that focus on the theoretical approach and practical approach. OPEK Physics instruction model is the instruction model based on practical approach by stimulating the practical skills of students. This study aims to examine the effect of the use of OPEK Physics instruction model on temperature and heat material to increase practical skill of the high school students. This study was conducted at SMAN 7 Yogyakarta by using pretest-posttest control group design. Practical skill of students are measured by tests and observations sheet. The results of this study is that there is a significant difference in the improvement of practical skill of the students who are taught by using OPEK Physics instruction model those who are taught not by using this intruction model.
\end{abstract}

Keywords: OPEK Physics Instruction Model, Temperature and Heat, Practical Skill

\begin{abstract}
Abstrak: Kontribusi pembelajaran fisika di sekolah dalam menghadapi Masyarakat Ekonomi ASEAN dapat diwujudkan dengan menerapkan model pembelajaran yang mengedepankan pendekatan teoritis dan pendekatan praktik. Model pembelajaran OPEK Fisika merupakan model pembelajaran yang berbasis pendekatan praktik dengan menstimulus practical skill siswa. Penelitian ini bertujuan untuk menguji pengaruh penggunaan model pembelajaran OPEK Fisika pada materi suhu dan kalor terhadap peningkatan practical skill siswa SMA. Penelitian ini dilakukan di SMAN 7 Yogyakarta dengan menggunakan desain penelitian pretest-posttest control group design. Practical skill siswa diukur dengan tes dan observasi. Hasil penelitian menunjukkan bahwa terdapat perbedaan peningkatan practical skill yang signifikan antara siswa yang dibimbing dengan model pembelajaran OPEK Fisika dan siswa yang tidak menggunakan model tersebut.
\end{abstract}

Kata kunci: Model Pembelajaran OPEK Fisika, Suhu dan Kalor, Practical Skill

\section{PENDAHULUAN}

Pemberlakuan Masyarakat Ekonomi ASEAN (MEA) merupakan langkah untuk meningkatkan daya saing negara-negara anggotanya termasuk Indonesia. Hal ini dapat menjadi peluang sekaligus tantangan bagi Indonesia. Adapun tantangan yang dihadapi adalah keterbatasan keterampilan sumber daya manusianya (Usman, 2016: 36). Salah satu solusi atas keterbatasan keterampilan ini adalah dengan pendidikan. Ruang lingkup pendidikan yang dimaksud adalah fokus pada pembelajaran di sekolah karena pada tahap ini terjadi peningkatan kualitas sumber daya manusia melalui proses belajar.

Keberhasilan pembelajaran sangat bergantung pada kesadaran, pengertian, komitmen, partisipasi dan dedikasi yang tinggi terutama bagi pendidik sebagai ujung tombak yang secara langsung berhadapan dengan siswa. Proses pembelajaran fisika yang dilakukan diharapkan tidak hanya mampu meningkatkan hasil belajar kognitif tetapi juga harus mampu meningkatkan keterampilan praktik (practical skill) serta terampil memecahkan masalah. Penerapan model pembelajaran yang tepat merupakan salah satu komponen penting untuk 
mencapai tujuan tersebut (Marzano, 2013: 7). Oleh sebab itu dalam pemilihan model pembelajaran dibutuhkan pertimbangan yang logis dan realistis.

Fisika sebagai ilmu dasar memiliki karakteristik yang mencakup fakta, konsep, prinsip, hukum, postulat, teori, dan metode ilmiah. Objek telaah fisika mengkaji peristiwa alam menggunakan metode ilmiah (Mundilarto, 2010: 4). Karakteristik fisika adalah berorientasi pada pengamatan, pemahaman, serta prediksi terhadap fenomena alam (Linney, 2008: 2) berupa gambaran gerak dan energi (Ewen, Schurter, \& Gunderson, 2012: 2), materi, panas, cahaya, serta fenomena alam yang lain termasuk planet, bintang, dan manusia (Trefil \& Hazel, 2010: 5). Sejalan dengan hal itu, fisika sebagai bagian ilmu sains fokus pada pengetahuan mengenai struktur alam, dapat menjelaskan fenomena alam menggunakan persamaan matematis, instrumen yang presisi, pengukuran (Tillery, Enger, \& Ross, 2007: 2), proses pembuktian teori menggunakan eksperimen (Buxton \& Provenzo, 2011: 297) dan hasilnya dapat juga dinyatakan dalam persamaan matematis (Zitzewitz, 201: 1). Dengan demikian pembelajaran fisika harus disesuaikan dengan karateristik fisika yang khas tersebut.

Model pembelajaran merupakan kerangka konseptual yang menggambarkan langkahlangkah yang sistematis dalam mengorganisasi pengalaman belajar untuk mencapai tujuan pembelajaran (Hamid, 2011: 1). Model pembelajaran memiliki beberapa ciri diantaranya yakni tujuan dan fase atau langkah-langkah (Eggen \& Kauchak, 2012: 7). Dapat disimpulkan bahwa model pembelajaran kerangka konseptual yang memuat langkah-langkah sistematis yang diterapkan untuk mencapai tujuan tertentu. Tujuan tersebut dapat berupa peningkatan hasil belajar kognitif dan keterampilan praktik (practical skill).

Model pembelajaran yang dapat diterapkan dalam pembelajaran fisika adalah berbasis ekperimen (Campbel et al, 2015: 159) dan latihan penelitian. Pembelajaran fisika di sekolah sudah selayaknya diajarkan dengan menggunakan model pembelajaran yang menekankan pada kegiatan eksperimen berbasis kegiatan ilmiah. Metode eksperimen dapat diartikan sebagai penyampaian materi pelajaran melalui latihan menggunakan alat ukur, bahan percobaan, dan perangkat percobaan baik secara individu ataupun kelompok (Hamid, 2011: 1). Kegiatan eksperimen yang diterapkan dalam pembelajaran fisika sebaiknya melibatkan kegiatan berbasis masalah (problem-based hands on activity) sebagai stimulus bagi pengembangan practical skill peserta didik (Sorgo \& Spernjak, 2012: 12). Model pembelajaran berbasis masalah dapat melatih siswa dalam memecahkan masalah dalam kehidupan sehari-hari.

Practical skill merupakan ketarampilan praktik yang berkaitan dengan kegiatan ilmiah seperti eksperimen. Dalam pembelajaran fisika, practical skill penting untuk dikembangkan karena karakteristik fisika itu sendiri adalah berbasis teori dan praktik. Practical skill terdiri dari beberapa kategori yakni: (1) keterampilan prosedural, (2) keterampilan observasi, (3) keterampilan menggambarkan, dan (4) keterampilan interpretasi (Kuhmar et al, 2009: 13-14). Practical skill harus dinilai dengan menggunakan teknik penilaian yang objektif. Ada beberapa keterampilan serta kemampuan yang dapat dinilai dalam practical skill meliputi: pengetahuan disertai pemahaman, aplikasi pengetahuan dan pemahaman, analisis dan evaluasi, dan keterampilan eksperimen serta investigasi. Masing-masing ketarampilan ini kemudian dispesifikasikan lagi ke dalam indikator operasional misalnya merencanakan langkah-langkah eksperimen, menganalisis fakta, serta menarik kesimpulan.

Practical skill dapat dikembangkan dalam pembelajaran fisika melalui metode laboratorium (Omotayo, Adedayo, \& Ayeni, 2014: 245), kegiatan e-laboratorium (Al Musawi, et al, 2015: 45) ataupun penyajian fenomena yang dekat dengan kehidupan seharihari. Penyajian fenomena ini memberikan dampak yang positif terhadap practical skill (Ogunleye \& Fasakin, 2011: 316). Practical skill telah menjadi bagian penting dalam fisika 
sehingga perlu dimaksimalkan dalam proses pembelajaran. Practical skill yang dimiliki tidak hanya bermanfaat dalam proses belajar di sekolah saja tetapi juga akan menjadi bekal dalam menghadapi tantangan di masa mendatang. Macam keterampilan yang terdapat di dalam practical skill dapat bersifat aplikatif dan relevan jika digunakan untuk memecahkan permasalahan dalam kehidupan sehari-hari.

Model pembelajaran OPEK fisika merupakan model pembelajaran hasil pengembangan. Model ini dikembangkan oleh Afriyanti (2016). OPEK diambil dari singkatan tahapan model pembelajaran yang meliputi: Orientasi masalah - Prediksi - Eksperimen - Kesimpulan. Model ini adalah hasil modifikasi model problem based learning dan pendekatan saintifik. Modifikasi dilakukan dengan tujuan memaksimalkan tujuan pembelajaran berupa peningkatan keterampilan praktikum dan sikap ilmiah siswa. Model pembelajaran OPEK Fisika dirancang dengan memperhatikan karakteristik fisika yakni berbasis teori dan praktik ilmiah. Lebih lanjut aspek yang dapat ditingkatkan melalui model pembelajaran ini adalah keterampilan siswa.

Penelitian ini bertujuan menerapkan model pembelajaran OPEK Fisika pada materi suhu dan kalor serta melihat pengaruhnya terhadap peningkatan practical skill siswa SMA. Hasil penelitian diharapkan dapat memberikan alternatif model pembelajaran yang tidak hanya menekankan pendekatan teoritis tetapi juga pendekatan praktik. Hal ini sebagai wujud kontribusi pembelajaran fisika di sekolah dalam mempersiapkan siswa-siswi agar tidak hanya memiliki pengetahuan secara teoritis saja tetapi juga practical skill. Lebih luas lagi, practical skill yang telah dimiliki dapat diaplikasikan guna menjawab tantangan Masyarakat Ekonomi ASEAN.

\section{METODE PENELITIAN}

Penelitian ini merupakan penelitian quasi eksperimen. Penelitian dilaksanakan di SMAN 7 Yogyakarta pada bulan April-Mei 2016. Populasi dalam penelitian ini adalah seluruh siswa kelas X IPA SMAN 7 Yogyakarta tahun ajaran 2015/2016. Sampel yang digunakan adalah satu kelas eksperimen dan satu kelas kontrol yang dipilih secara acak. Semua perlakuan yang diberikan pada kelas eksperimen sama kecuali pada model pembelajaran OPEK Fisika. Pada kelas eksperimen, model pembelajaran yang digunakan adalah model pembelajaran OPEK Fisika.

Practical skill diukur dengan menggunakan lembar observasi dan tes tertulis. Lembar observasi menggunakan rating scale dengan skala 4. Jenis tertulis yang digunakan adalah pilihan ganda. Practical skill yang diukur terdiri dari beberapa kategori. Dalam penelitian ini kategori practical skill yang diukur diadaptasi dari Kumar et al (2009: 13) dengan kisi-kisi seperti pada Tabel 1.

Tabel 1. Kisi-kisi Soal dan Lembar Observasi Practical Skill

\begin{tabular}{clcc}
\hline \multirow{2}{*}{ No. } & \multirow{2}{*}{ Kategori Practical Skill } & \multicolumn{2}{c}{ Jumlah Butir } \\
\cline { 3 - 4 } & & Soal & Lembar Observasi \\
\hline 1 & Keterampilan prosedural & 6 & 4 \\
2 & Keterampilan observasi & 6 & 4 \\
3 & Keterampilan menggambar & 2 & 4 \\
4 & Keterampilan menginterpretasi & 6 & 4 \\
\hline \multicolumn{2}{c}{ Jumlah } & 20 & 16 \\
\hline
\end{tabular}

Pengukuran dilakukan di awal pembelajaran sebagai pretest dan di akhir pembelajaran sebagai posttest. Desain penelitian yang digunakan adalah pretest-posttest control group design (Wiersma \& Jurs, 2009: 146) yang disajikan pada Tabel 2. 
Tabel 2. Desain Penelitian

\begin{tabular}{lccc}
\hline \multicolumn{1}{c}{ Kelas } & Pretest & Perlakuan & Posttest \\
\hline Eksperimen & $\mathrm{O}_{1}$ & $\mathrm{X}_{1}$ & $\mathrm{O}_{2}$ \\
Kontrol & $\mathrm{O}_{1}$ & $\mathrm{X}_{2}$ & $\mathrm{O}_{2}$ \\
\hline
\end{tabular}

Keterangan:

$\mathrm{O}_{1}$ : Pretest

$\mathrm{O}_{2}$ : Postest

$\mathrm{X}_{1}$ : Menggunakan model pembelajaran OPEK Fisika

$\mathrm{X}_{2}$ : Menggunakan model pembelajaran direct instruction

Data peningatan practical skill untuk masing-masing kelas ekspperimen dan kelas kontrol ditentukan dengan melihat nilai gain ternormalisasi berdasarkan persamaan berikut (Hake, 1998).

$$
g=\frac{S_{f}-S_{i}}{100-S_{i}}
$$

Keterangan: $\quad S_{f}=$ final score (skor akhir yang diperoleh dari posttest)

$S_{i}=$ initial score (skor awal yang diperoleh dari pretest)

$g=$ gain (peningkatan)

Ada atau tidaknya perbedaan peningkatan practical skill siswa antara kelas eksperimen dan kelas kontrol dianalisis dengan independent-sample t-test dengan asumsi data berasal dari populasi yang terdistribusi normal dan homogen. Jika data berasal dari populasi yang tidak terdistribusi normal, maka digunakan uji nonparametrik Mann-Whitney U. Seluruh uji statistik dilakukan dengan bantuan program komputer SPSS for windows dengan taraf kepercayaan 95\%. Hipotesis yang diuji pada penelitian ini adalah sebagai berikut.

Ho : Tidak terdapat perbedaan yang signifikan pada peningkatan practical skill antara kelas eksperimen dan kelas kontrol.

Ha : Terdapat perbedaan yang signifikan pada peningkatan practical skill antara kelas eksperimen dan kelas kontrol.

\section{HASIL DAN PEMBAHASAN}

Model pembelajaran OPEK Fisika merupakan model pembelajaran hasil pengembangan yang dirancang khusus untuk pembelajaran fisika. Model pembelajaran ini berbasis masalah dan pendekatan saintifik. Ada beberapa komponen model pembelajaran OPEK Fisika yang harus dipahami agar penerapan model pembelajaran yang dikembangkan Afriyanti (2016) ini dapat berjalan dengan lancar, yakni: 1) sintaks (tahap pembelajaran), 2) sistem sosial (pola hubungan anatara guru dan siswa), 3) prinsip reaksi (bentuk respon guru terhadap siswa pada pembelajaran), 4) sistem pendukung (alat dan bahan pendukung pembelajaran), 5) dampak instruksional (tujuan pembelajaran yang dapat dicapai). Model pembelajaran ini telah dirancang sedemikian rupa untuk menstimulus keterampilan siswa. Kegiatan eksperimen yang dilibatkan dalam pembelajaran akan mendukung peningkatan practical skill siswa.

Pada penelitian ini, model pembelajaran OPEK Fisika diterapkan dalam pembelajaran fisika di kelas eksperimen pada materi suhu dan kalor. Pada saat pembelajaran, siswa dibekali lembar kerja siswa (LKS) yang telah dirancang berdasarkan model pembelajaran OPEK Fisika. LKS ini berguna untuk membantu siswa dalam memecahkan masalah yang diberikan dengan menggunakan metode ilmiah berbasis kerja praktik. LKS yang diberikan dirancang 
untuk materi suhu dan kalor. Pembelajaran untuk materi suhu dan kalor dilakukan selama 4 kali 2 jam pelajaran.

Practical skill diukur dengan menggunakan teknik tes berupa soal pilihan ganda dan lembar observasi. Kedua teknik pengukuran ini digunakan agar hasil yang diperoleh lebih komperhensif. Instrumen berupa soal pilihan ganda dan lembar observasi telah divalidasi oleh ahli. Data yang diperoleh dari lebar observasi masih berupa skala ordinal sehingga dikonversi menjadi skala interval dengan metode suksesif interval (MSI). Skor yang diperoleh dari tes tertulis dan observasi dijumlahkan kemudikan dicari reratanya. Peningkatan practical skill dilihat dari nilai pretest dan posttest yang kemudian dinyatakan dengan nilai gain ternormalisasi. Analisis dilakukan dengan bantuan program komputer SPSS for windows pada taraf signifikansi 95\%.

Pengaruh penerapan model pembelajaran OPEK Fisika pada materi suhu dan kalor terhadap peningkatan practical skill siswa kelas X IPA SMA N 7 Yogyakarta dianalisis dengan membandingkan peningkatan practical skill siswa pada kelas eksperimen yang menggunakan model pembelajaran OPEK Fisika dan kelas kontrol yang tidak menggunakan model pembelajaran tersebut. Nilai gain diperoleh perhitungan skor pretest dan posttest kelas eksperimen dan kelas kontrol. Rata-rata peningkatan (gain) practical skill pada kelas eksperimen dan kelas kontrol disajikan pada Tabel 3.

Tabel 3. Hasil Pengukuran Practical Skill Siswa

\begin{tabular}{cccccc}
\hline \multirow{2}{*}{ No. } & \multirow{2}{*}{ Kelas } & Jumlah & \multicolumn{3}{c}{ Rata-rata } \\
\cline { 3 - 6 } & & Siswa & Pretest & Posttest & Gain \\
\hline 1 & Eksperimen & 30 & 20,16 & 65,46 & 0,57 \\
2 & Kontrol & 30 & 25,50 & 46,66 & 0,26 \\
\hline
\end{tabular}

Tahap awal yang perlu dilakukan adalah uji asumsi. Uji ini dilakukan terlebih dahulu untuk mengetahui apakah data nilai gain practial skill pada kedua kelas tersebut berasal dari populasi yang terdistribusi normal dan homogen. Hasil uji normalitas disajikan pada Tabel 4.

Tabel 4. Hasil Uji Normalitas Data

\begin{tabular}{cccccc}
\hline \multirow{2}{*}{ No } & \multirow{2}{*}{ Kelas } & \multicolumn{2}{c}{ Kolmogorov-Smirnov } & \multirow{2}{*}{ Kesimpulan } \\
\cline { 3 - 5 } & & Statistik & df & Sig. & \\
\hline 1 & Eksperimen & 0,124 & 30 & 0,200 & Normal \\
2 & Kontrol & 0,185 & 30 & 0,011 & Tidak Normal \\
\hline
\end{tabular}

Data gain pada kelas eksperimen terdistribusi normal sedangkan pada kelas kontrol tidak terdistribusi normal. Dengan demikian asusmsi normalitas data tidak terpenuhi sehingga analisis menggunakan $t$-test tidak dapat dilakukan. Analisis dilanjutkan dengan menggunakan uji nonparametrik Mann-Whitney U. Tujuan pengujian tetap sama yakni mengetahuii ada tidak perbedaan peningkatan practical skill anatar kelas eksperimen dan kelas kontrol. Hasil uji Mann-Witney U terhadap gain pada kedua kelas disajikan pada Tabel 5.

Tabel 5. Uji Hipotesis

\begin{tabular}{lrc}
\hline \multicolumn{1}{c}{ Data Uji } & Practical Skill & Kesimpulan \\
\hline Mann-Whitney U & 47,000 & Ho ditolak \\
Wilcoxon W & 512,000 & (terdapat perbedaan peningkatan practical skill \\
Z & $-5,965$ & yang signifikan antara kelas eksperimen dan \\
Asymp. Sig. (2-tailed) & 0,000 & kelas kontrol) \\
\hline
\end{tabular}


Hasil uji Mann-Whitney U menunjukkan terdapat perbedaan yang signifikan pada peningkatan practical skill siswa antara kelas eksperimen yang menggunakan model pembelajaran OPEK fisika dan kelas kontrol yang tidak menggunakan model pembelajaran tersebut. Berdasarkan rata-rata nilai gain yang disajikan pada Tabel 3, diketahui bahw ratarata gain kelas eksperimen lebih tinggi dibandingkan gain kelas kontrol. Dengan demikian dapat disimpulkan bahwa model pembelajaran OPEK Fisika dapat meningkatkan practical skill siswa kelas X IPA di SMAN 7 Yogyakarta.

Hasil penelitian ini sejalan dengan yang diungkapkan Etherington (2011: 38) yakni penggabungan antara pendekatan saintifik dan model PBL menjadi satu model pembelajaran, cocok diterapkan dalam pembelajaran sains termasuk fisika. Model pembelajaran OPEK Fisika merupakan hasil modifikasi keduanya dimana kegiatan eksperimen berbasis kerja ilmiah sangat ditekankan. Pada tahap melakukan kegiatan eksperimen siswa melakukan kegiatan mencari dan menguji secara langsung apa yang akan dipecahkan (Joyce, Weil, \& Calhoun, 2009: 207). Dalam kegiatan eksperimen ini tentu saja akan melibatkan berbagai macam keterampilan siswa, mulai dari keterampilan prosedural, keterampilan observasi, dan keterampilan interpretasi yang merujuk pada practical skill. Model pembelajaran OPEK Fisika menekankan pada pendekatan teoritik dan praktik sehingga dapat mendukung peningkatan practical skill siswa.

Dalam penerapan pembelajaran di kelas, model pembelajaran OPEK fisika memiliki kelebihan dan kekurangan. Adapun kelebihan tersebut diantaranya: 1) model pembelajaran merisyaratkan penyajian masalah yang kontektual untuk dipecahkan oleh siswa; 2) mempermudah siswa melakukan kegiatan ilmiah dengan adanya LKS; 3) langkah-langkah dalam model pembelajaran menstimulus siswa untuk menggunakan keterampilan praktik (practical skill). Model pembelajaran memiliki aspek tertentu yang terkadang dianggap sebagai kekurangan yakni memfasilitasi siswa untuk melakukan kegiatan eksperimen. Sistem pendukung seperti peralatan laboratorium yang terbatas tentu saja akan menghambat penerapan model ini di kelas. Hal ini dapat ditangani dengan menggunakan alat dan bahan yang ada di sekitar. Guru harus kreatif membaca apa yang dapat dimanfaatkan untuk menciptakan proses pembelajaran yang kondusif.

\section{SIMPULAN}

Model pembelajaran OPEK Fisika telah berhasil diterapkan pada pembelajaran fisika di sekolah untuk materi suhu dan kalor. Rata-rata peningkatan (gain)pada kelas eksperimen menunjukkan nilai yang lebih tinggi dibandingkan dengan kelas kontrol.Ada perbedaan yang signifikan pada peningkatan practical skill siswa antara kelas eksperimen yang dibimbing menggunakan model pembelajaran OPEK Fisika dan kelas kontrol yang tidak menggunakan model pembelajaran tersebut pada pembelajaran fisika untuk materi suhu dan kalor di kelas $\mathrm{X}$ IPA SMAN 7 Yogyakarta tahun ajaran 2015/2016.

\section{SARAN}

Model pembelajaran OPEK Fisika dapat diimplementasikan lebih lanjut dalam pembelajaran fisika guna melihat pengaruhnya terhadap variabel lain seperti keterampilan proses sains dan juga prestasi kognitif siswa. Dalam rangka penerapan model pembelajaran OPEK di sekolah, disarankan kepada pendidik untuk membaca secara keseluruhan petunjuk penggunaan model. Hal ini bertujuan agar dimiliki pemahaman yang menyeluruh dan mendalam tentang model pembelajaran OPEK. Perlu diperhatikan pula pengaturan waktu, penyediaan alat dan bahan untuk kegiatan eksperimen agar tujuan pembelajaran dapat tercapai dengan maksimal. 


\section{DAFTAR PUSTAKA}

Afriyanti. (2016). Pengembangan model pembelajaran OPEK pada pembelajaran fisika untuk meningkatkan practical skill dan sikap ilmiah siswa SMA. Tesis Magister tidak diterbitkan. Yogyakarta: Universitas Negeri Yogyakarta.

Al Musawi, A., Ambusaidi, A., Al-Balushi, et al. (2015). Effectiveness of e-lab use in science teaching at the Omani schools. The Turkish Online Journal of Educational Technology, 14(1), 45-52.

Buxton, A.C., \& Provenzo, F.E. (2011). Teaching acence elementary \& middle shool a cognitive and cutural approach. Tousand Oaks: SAGE Publications, Inc.

Campbell,T., Seok Oh, P., Maughn, M., et al. (2015). A review of modeling pedagogies: Pedagogical functions, discursive acts and technology in modelung instruction. Eurasia Journal of Mathematics, Science \& Technology Education, 11(1), 159-176.

Eggen, P., \& Kauchak, D. (2012). Strategi dan model pembelajaran: mengajar konten dan keterampilan berfikir. (Terjemahan Satrio Wahono). Boston: Pearson. (Buku asli diterbitkan tahun 2012).

Etherington, M.B. (2011). Investigate ptimary science: A problem based learning approach. Australian Journal of Teacher Education, 36(9), 35-57.

Ewen, D., Schurter, N., \& Gundersen, E.P. (2012). Applied physics tenth edition. Washington: Prentice Hall.

Hamid, A.A. (2011). Pembelajaran fisika di sekolah. Yogyakarta: FMIPA-UNY

Joyce, B., Weill, M., \& Calhoun, E. (2009). Model of teaching (7 $7^{\text {th }}$ ed.). Boston: Pearson Education.

Kuhmar, A., Sehgal, N.K., Gambhir, V.G., et al. (2009). Assesment of practical skill in science. New Delhi: Shiksha Kendra, Community Centre.

Linney. (2008). Physics, astronomy and astrophysics. Quality Assurance Agency for Higher Education, ISBN 9781844828050.

Mundilarto. (2010). Penilaian hasil belajar fisika. Yogyakarta: Jurusan Pendidikan Fisika FMIPA UNY.

Marzano, R. (2013). Seni dan ilmu pengajaran. Jakarta: PT. Indeks.

Ogunleye, B.O., \& Fasakin, A.O. (2011). Everyday phenomena in physics education: Impact on male and female students' echievement, attitude adn practical skills in urban and peri-urban setting in Nigeria. Pakistan Journal of Social Science, 8(6), 316-324.

Omotayo, K., Adedayo, J., \& Ayeni, M. (2014). Science education reform effort: effect of utilsing laboratory method of instruction on students' academic performance in science: Asian Journal of Education \& E-Learning, 22(3), 245-249.

Sorgo, A., \& Spernjak, A. (2012). Practical work in biology, chemistry, and physics at lower secondary and general upper secondary school in Slovenia. Eurasia journal of Mathematics, Science \& Technology Education, 8(1), 11-19.

Tillery, B.W., Enger, E.D., \& Ross, F.D. (2007). Integrated science (4th ed.): A copanion to school experience. Abingdon: Routledge.

Trefil, J. \& Hazen, R.M. (2010). The science: an integrated approach. Hoboken, New Jersey: 
John Wiley \& Sons.

Usman, F. (2016). Masyarakat Ekonomi ASEAN (MEA) dan daya saing investasi Indonesia. Jurnal Lingkar Widyaiswara, 3(1),33-36. Diambil dari http://juliwi.com/published/E0301/Juliwi0301_33-36.pdf

Wiersma, W., Purwanti, W., \& Susilowati. (2011). Research methods in education, nineth edition. USA: Pearson Education, Inc.

Zitzewitz, P. (2011). The handy physics answer book (2 ${ }^{\text {nd }}$ ed.). New York: Visible Ink Press. 